\title{
Coupling Analysis of Connectivity between Coarse Sediment Source Areas and Deposition Area in the Yellow River, China
}

\author{
Li He*, Ming Yan \\ Key Laboratory of Water Cycle and Related Land Surface Processes, Institute of Geographic Sciences \\ and Natural Resources Research, Chinese Academy of Sciences, Beijing, China
}

Received: 31 August 2017

Accepted: 18 January 2018

\begin{abstract}
As a coupling river system, watershed management in sediment source areas may influence downstream reach. However, the connectivity between water and sediment retention (WSR) in two coarse sediment source areas (tributaries entering the Inner Mongolia Reach, IMR, and tributaries entering the Middle Yellow River, MYR) and deposition in the Lower Yellow River (LYR) have rarely been compared. Experiential fitted models for each river segment (IMR, MYR, and LYR) are loosely linked to investigate the coupling relationship between source areas and deposition area. Analysis shows that, at the zonal scale, the connectivity between WSR in different zones and deposition reduction in different river reaches differs. WSR in tributaries of the IMR may benefit the local channel (IMR) with a priority ratio, and WSR in the stem channel of the IMR may benefit both the local (IMR) and the lower (LYR) channels with almost the same magnitude. WSR in the MYR may benefit the local channel (LT reach) and the lower channel (LYR), while the LYR has more propriety. At the zonal scale, the temporal scales over which changes in hillslopes occur also differ, as WSR in the IMY and MYR during the non-flood season may also contribute to deposition reduction in the MYR and LYR. In total, the loosely linked model may provide information of sediment along the whole river network.
\end{abstract}

Keywords: coarse sediment source area, deposition area, loosely coupled, experiential models, Yellow River

\section{Introduction}

Coupling within fluvial systems is a fundamental property affecting the down-system transmission. The coupling concept was originally introduced to geomorphology with widespread attention by Brunsden and Thornes [1]. Recently, it has received attention in the

*e-mail: heli@igsnrr.ac.cn context of coupling between hillslopes and channels [2$6]$. The coupled connectivity reflects how the channel network responds to hillslope-derived disturbance in the fluvial system, and is therefore important in determining the geomorphic response to human-induced environmental change [71].

The transmission of sediment governs the coupling relationships between hillslopes and headwater sources, and from reach to reach of the channel system [8]. At zonal scale, coupling mechanisms affect the transfer 
of sediment between the major sediment-source, transport and depositional zones of the fluvial system [9]. Examples of studies at the zonal scale include studies relating to upland catchments and lowland rivers (e.g., $10,11)$, and some involving considerations of sediment provenance (e.g., 12, 13).

Linking models are expected to produce better information about the natural system and enhance the accuracy and flexibility in describing the real world, as it uses the best qualities of each model [14-16]. Linking models can also help determine the spatial sources of sediment in upland watershed, and appropriate management can be implemented to address problems in the downstream channel [15]. The advantages of the loosely coupled model have been widely verified and utilized to address various objectives involving a complex network of river systems [15-19]. When appropriate models are chosen for each task, the method of properly and externally linking models for various components of the natural network system may represent the integrated nature of entire watershed systems and provide good management decisions [20,21].

The Yellow River (YR) in China is well known for excessive sediment load and insufficient stream flow, and also for the corresponding continuous aggradations in the lower reach [22, 23]. There are two groups of tributaries where eroded sediment are from relatively coarse tributaries entering the stem channel of Sanhuhekou-Toudaoguai (Inner Mongolia River reach, IMR) and the Toudaoguai-Longmen (TL river reach). Sediment-water retaining (SWR) by both engineering and non-engineering takes important events in the YR system. More efforts have focused on the coarse sediment source areas recently [24-26]. Previous research indicates that effects of SWR are not only local but widespread, as changed water-sediment conditions may transmit the effects of environmental change through the system. Various methods have been adopted to investigate the coupling behavior of zonalscale source-sink relationship, formula fitting (e.g., 27, 28), numerical simulation (e.g., 17, 29), and field survey (e.g., 30, 31). However, the relationship between SWR in these two coarser sediment source areas (tributaries entering IMR and TL river reaches) and deposition in the lower channel has rarely been compared.

The objective of this study is to analyze the coupling connectivity between coarse sediment source areas and the channel network. Various experimental equations have been established to examine the local-scale coupling [22, 32, 33]. Therefore, experimental formulas are linked to examine zonal-scale connectivity. Firstly, experimentally fitted models are chosen for the IMR, the middle Yellow River (MYR), and the Lower Yellow River (LYR), respectively. Then the influence of WSR in different regions on the deposition are analyzed by the loosely coupled models. As some inner simplifications taken during the analysis procedure, the influences of these uncertainties are then analyzed.

\section{Study Area and Data}

\section{Study Area Condition}

The two coarse sediment source areas in the YR basin (Fig. 1), tributaries entering the IMR, and tributaries entering the TL river reach are introduced separately. Another characteristic of these two groups of tributaries is that sediments from these two regions are contributed to by frequently occurring hyper-concentrated floods [25].

The first group is the ten small tributaries entering the stem channel of IMR [34]. In these ten tributaries, hyper-concentrated floods occurr frequently (i.e., $87.1 \%$ for Xiliugou River), which are characterized with large peak values of discharge and concentration (i.e., $6940 \mathrm{~m}^{3} / \mathrm{s}$ and $1380 \mathrm{~kg} / \mathrm{m}^{3}$, respectively, for the Xiliugou River) with a sharp rise and fall $[26,35]$. The annual SSL of these ten tributaries is approximately $0.256 \times 10^{8} \mathrm{t}(1953-2010)$, and approximately $25 \%$ of the total SSL at the IMR reach are provided by these ten tributaries, even though the total drainage area of these ten tributaries is approximately $1.1 \times 10^{4} \mathrm{~km}^{2}$ [36]. More importantly, the mean diameters of these ten tributaries are relatively coarse, and the ratio of particles coarser than $0.05 \mathrm{~mm}$ is approximately $60 \%$ [26].

The second group is tributaries entering the TL river reach who are the main component of the sediment source area (SSA) in the YR basin. The average sediment delivery modulus in the SSA is approximately $980.5 \mathrm{t} /\left(\mathrm{km}^{2} \cdot \mathrm{a}\right)(2000-2010)$. The drainage area of SSA is approximately $9 \times 10^{4} \mathrm{~km}^{2}$, and $63.3 \%$ of the total sediment entering the lower channel (denoted by the sum of sediment amount measured at Longmen, Huaxian, Hejin, and Zhuangtou hydrological stations) are eroded from this area, and the ratio for coarse sediment is $87 \%$ [37] The four largest tributaries in SSA are the Huangfu, Kuye, Wuding, and Yan rivers.

There are another two tributaries with high sediment modulus: the upper drainage area of the Beiluo and Jing rivers. These two tributaries enter the YR at Tongguan station and the Wei River at Xianyang station, while the Wei River joins the YR at Tongguan station. Thus, these two tributaries (the Beiluo and Jing) can be viewed as entering the YR at Tongguan station (as shown in Fig. 1b), which may contribute to deposition in the Longmen-Tongguan (LT) reach with limited magnitude. Thus, the whole MYR can be divided into TL and LT river reaches, and sediments are eroded from the drainage area of TL river reach and transported through the LT river reach, where deposition occurred.

\section{Data Collection}

According to data measured and published by the Yellow River Conservancy Commission (YRCC), the water runoff and SSL measured at controlling stations are collected. Controlling stations are Sanhuhekou, Toudaoguai, Longmen, Hejin (controlling station of the 
a)

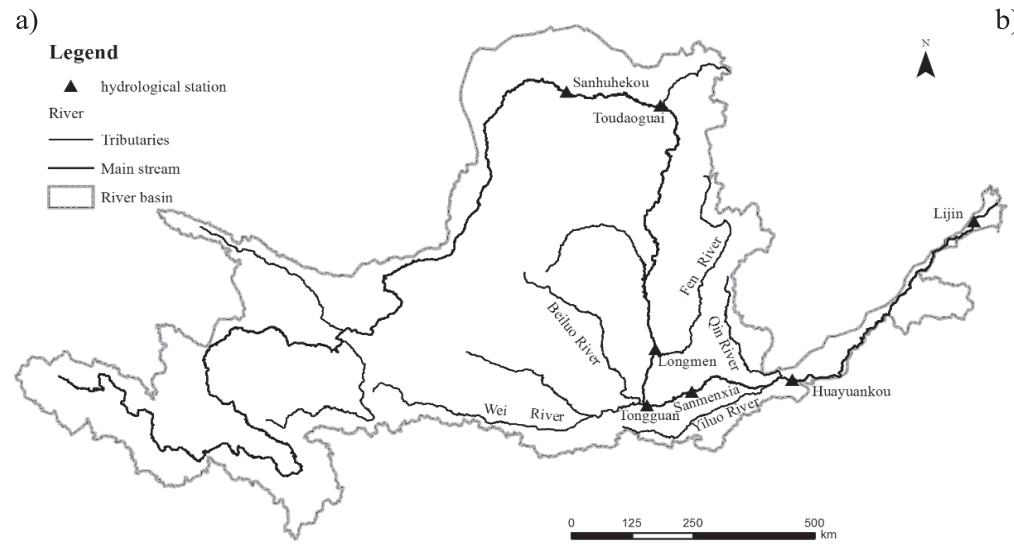

b)

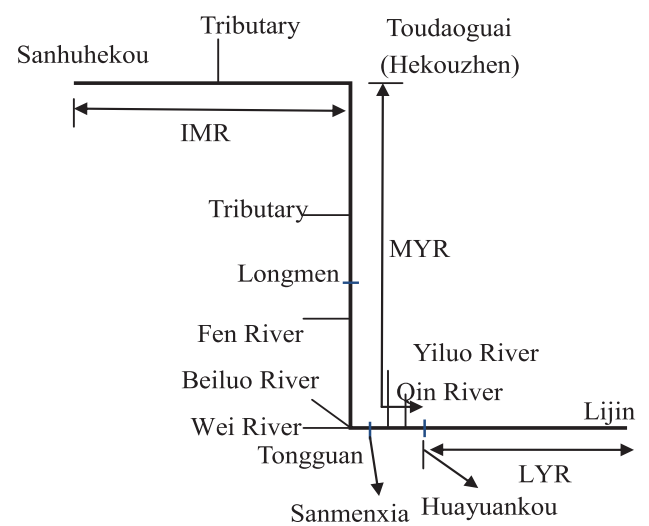

Fig. 1. Drainage area a) and sketch map b) of the Yellow River.

Fen River), Sanmenxia, Heishiguan (controlling station of the Yiluo River), and Xiaodong (controlling station of the Qin River), as summarized in Table 1. The values of water runoff and SSL in flood season are data measured at 2008. Tributaries entering the MYR can be estimated by summing up data from the Huangfu, Kuye, Wuding, and Yan rivers, which are the four largest tributaries in the SSA [38]. Water runoff and SSL of tributaries entering the IMR are data drawn from $\mathrm{Wu}$ [39].

\section{Methodology}

\section{Deposition Estimation in Each River Reach}

For each river reach, sediment deposition can be estimated by formula

$$
\Delta \mathrm{W}_{s}=f\left(W_{s}, W\right)
$$

in which $\Delta \mathrm{W}_{S}$ represents deposition in the river reach; $W$ and $W_{\mathrm{S}}$ represent water runoff and SSL entering the river reach, respectively; and $f()$ is the connectivity between deposition and incoming water/sediment. In order to make it more understandable, subscripts 1,2 , and 3 are adopted to represent the reach of IMR, MYR, and LYR, respectively. The relationship of water runoff and SSL between adjacent river reaches can be estimated by water-sediment balance.

For the first river reach (i.e., IMR), the water-sediment balance can be expressed as:

$$
\begin{gathered}
W_{S(i)}=W_{S(c)}+W_{S(t, i)} \quad(i=1) \\
W_{(i)}=W_{(c)}+W_{(t, i)} \quad(i=1)
\end{gathered}
$$

in which $W_{S(i)}$ and $W_{(i)}$ represents annual SSL and water runoff entering the river reach, respectively; $W_{S(e)}$ and $W_{(e)}$ represents annual SSL and water runoff measured at controlling station of the stem channel, respectively, as subscript $c$ indicates controlling station;

\begin{tabular}{|c|c|c|c|c|c|}
\hline \multirow{2}{*}{ Station } & \multirow{2}{*}{ River } & \multicolumn{2}{|c|}{ Annual data* } & \multicolumn{2}{|c|}{ Flood season $(\%)^{* *}$} \\
\hline & & Water runoff $\left(10^{8} \mathrm{~m}^{3}\right)$ & $\operatorname{SSL}\left(10^{8} \mathrm{t}\right)$ & Water runoff $\left(10^{8} \mathrm{~m}^{3}\right)$ & $\operatorname{SSL}\left(10^{8} \mathrm{t}\right)$ \\
\hline Sanhuhekou & Yellow River & 169 & 0.51 & 38.00 & 53.00 \\
\hline Tributaries in IMR ${ }^{* * *}$ & 1.73 & 0.292 & - & - & \\
\hline Toudaoguai & Yellow River & 152.1 & 0.393 & 38.37 & 46.22 \\
\hline Tributaries in $\mathrm{MYR}^{* * * *}$ & 15.655 & 1.851 & - & - & \\
\hline Longmen & Yellow River & 189.8 & 4.33 & 36.78 & 35.10 \\
\hline Hejin & Fen River & 4.813 & 0.026 & - & - \\
\hline Sanmenxia & Yellow River & 232.5 & 6.798 & 38.00 & 55.52 \\
\hline Heishiguan & Yiluo River & 17.6 & 0.016 & - & - \\
\hline Xiaodong & Qin River & 4.896 & 0.012 & - & - \\
\hline
\end{tabular}
and $W_{S(t, i)}$ and $W_{(t, i)}$ mean annual SSL and water runoff

Table 1. Characteristics of the controlling stations.

*Annual data are measured during 1987-2005; ${ }^{* *}$ data for flood season are measured in 2008; ${ }^{* * *}$ average data during 1987-2010, after Wu [39]; ${ }^{* * * *}$ data are summed up by Huangfu, Kuye, Wuding, and Yan rivers. 
from tributaries entering the river reach, respectively, as subscript $t$ indicates tributary.

For the following two river reaches (i.e., MYR and LYR), the water-sediment balance can be expressed as:

$$
\begin{gathered}
W_{S(i)}=W_{S(i-1)}-\Delta W_{S(i-1)}+W_{S(t, i)} \quad(i=2,3) \\
W_{(i)}=W_{(i-1)}+W_{(t, i)} \quad(i=2,3)
\end{gathered}
$$

in which $\Delta W_{S(i-1)}$ indicates deposition in the (i-1)th river reach.

The empirically fitted formulas for estimating depositions $\Delta W_{S(i)}(i=1-3)$ in different reaches of the YR are summarized in Table 2 [40-44]. The sediment load and water runoff down the Longyangxia Reservoir has been changed dramatically after its operation in 1986 [25]. Data measured after 1986 are adopted to fit formulas in IMR, and the values of $R^{2}$ are 0.820 and 0.892 , respectively [40]. The slope of the TL river reach is approximately 0.84 , and sediment deposition in this river reach can be ignored as its canyon character [45, 46]. Thus, deposition in the MYR is approximately the same as deposition in the LT river reach. Besides, no empirical formulas have been fitted to estimate the annual deposition in LT river reach, and deposition in MYR during the non-flooding season can be ignored.

For these three reaches, the amount of water runoff and SSL in flood season (July to October) is simplified as annual values with a certain proportion. Water runoff and SSL in flood season can be estimated as:

$$
\begin{aligned}
& W_{s}^{\prime}=\alpha W_{s} \\
& W^{\prime}=\beta W
\end{aligned}
$$

...where $\alpha$ and $\beta$ are coefficients. The values of $\alpha$ and $\beta$-coefficients are simplified as data measured at the controlling station of each river reach in 2008 . The water runoff and SSL measured at Sanhuhekou Hydrological Station take as a major part of the total runoff and SSL entering the IMR, the same as Longmen station for MYR and Sanmenxia station for LYR. The coefficient values are listed in Table 1.

\section{Estimating Reduced Deposition (RD) and Scenario Design}

Empirically fitted formulas have been established to estimate the corresponding deposition in each river reach (IMR, MYR, and LYR) [41-45]. Linking already-existing experiential formulas externally can be adopted to estimate the coupling effects of SWR in different regions on the channel system. SWR measurements are designed to be implemented in four different zones: drainage area of tributaries entering IMR (Zone 1), the stem channel of IMR (Zone 2), drainage area of tributaries entering MYR (Zone 3), and the stem channel of LYR (Zone 4). The two coarse sediment source areas have been included as Zones 1 and 3. SWR in Zones 1 and 3 may be caused by soil-retaining dam or plants. SWR in Zones 2 and 4 may be caused by reservoir, water division, or other effects that may reduce the inflow runoff and SSL.

The coupling connectivity can be evaluated with amounts of $\mathrm{RD}$, with a positive value indicating that deposition in the river reach may be reduced by SWR measurements, and a negative value indicating that deposition in the river reach may be larger than that of before the SWR measurements. In order to make it more comparable with existing results by former researchers, the RD is transformed to reduced deposition caused by per unit ton of sediment or cubic meter of water runoff (RDP).

The amounts of decreased inflow water runoff (IWR) and inflow suspended sediment load (ISSL) in these four zones are supposed to be of the same magnitudes. SWR in Zone 1 is taken as a benchmark. For the ten

Table 2. Formulas for estimating deposition in each river reach.

\begin{tabular}{|c|c|c|c|c|c|}
\hline$i$ & River reach & Annual deposition $\left(10^{8} \mathrm{t}\right)$ & Deposition during flood season $\left(10^{8} \mathrm{t}\right)$ & Data & References \\
\hline 1 & $\begin{array}{c}\text { IMR } \\
\begin{array}{c}\text { (Sanhuhekou- } \\
\text { Toudaoguai) }\end{array}\end{array}$ & $\begin{array}{c}\Delta W_{S(1)}=0.343 W_{S(1)}-0.004 W_{(1)} \\
+0.968 W_{S(t, 1)}+0.445\end{array}$ & $\begin{array}{c}\Delta W_{S(1)}^{\prime}=0.402 W_{S(1)}^{\prime}-0.004 W_{(1)}^{\prime} \\
+0.968 W_{S(t, 1)}^{\prime}+0.149\end{array}$ & $1953-2010$ & {$[40]$} \\
\hline $\begin{array}{c}\text { MYR } \\
\text { (Longmen-Tong- } \\
\text { guan) }\end{array}$ & $\begin{array}{c}\text { Supposed to be the same } \\
\text { as flood-season one. }\end{array}$ & $\Delta W_{S(2)}^{\prime}=\kappa\left(\frac{W_{S(2)}^{\prime}}{\left.W_{(2)}^{\prime}\right)^{\alpha}}\right.$ & $1986-2012$ \\
\hline 3 \\
$\begin{array}{c}\text { LYR } \\
\text { (Sanmenxia-Lijin) }\end{array}$ & $\begin{array}{c}\Delta W_{S(3)}=0.507 W_{S(3)}-0.0192 W_{(3)} \\
+3.84\end{array}$ & $\begin{array}{c}\Delta W_{S(3)}^{\prime}=0.523 W_{S(3)}^{\prime}-0.025 W_{(3)}^{\prime} \\
+2.352\end{array}$ & $1950-1997$ & {$[42,43]$} \\
\hline
\end{tabular}

...where superscript ' represents value in flood season. $W_{S(1)}$ and $W_{S(1)}$ ' can be estimated by summing up SSL at Sanhuhekou and SSL by wind during the reach of Sanhuhekou-Toudaoguai reach (tributaries are not included); $W_{S(t, 1)}$ and $W_{S(t, 1)}$ ' represents measured SSL of tributaries $\left(10^{8} \mathrm{t}\right) ; W_{S(2)}$ and $W_{S(2)}$ ' can be estimated by summing up data measured at Longmen and Hejin; the fitted values of $\kappa$ and $\alpha$ are 168.1553 and 1.7634, respectively (1986-2012) [44]. $W_{(3)}{ }^{\prime}, W_{(3)}, W_{S(3)}{ }^{\prime}$, and $W_{S(3)}$ can be estimated by summing up data measured at Sanmenxia Reservoir, Heishiguan, and Xiaodong [42]. 
Table 3. Water runoff and SSL of the IMR.

\begin{tabular}{|c|c|c|c|c|}
\hline & \multicolumn{2}{|c|}{ Annual } & \multicolumn{2}{c|}{ Flood season } \\
\cline { 2 - 5 } & $\begin{array}{c}\text { Water runoff } \\
\left(10^{8} \mathrm{~m}^{3}\right)\end{array}$ & $\begin{array}{c}\text { SSL } \\
\left(10^{8} \mathrm{t}\right)\end{array}$ & $\begin{array}{c}\text { Water runoff } \\
\left(10^{8} \mathrm{~m}^{3}\right)\end{array}$ & $\begin{array}{c}\mathrm{SSL} \\
\left(10^{8} \mathrm{t}\right)\end{array}$ \\
\hline Sanhuhekou & 169 & 0.51 & 64.53 & 0.27 \\
\hline $\begin{array}{c}\text { Tributaries in } \\
\text { IMR }\end{array}$ & 1.71 & 0.19 & 1.71 & 0.91 \\
\hline MYR & 217 & 5.11 & 79.88 & 1.79 \\
\hline LYR & 303 & 6.84 & 115.36 & 3.80 \\
\hline
\end{tabular}

small tributaries in IMR, the concentration of flood events is relatively high [35], and the management of water and sediment in these tributaries may lead to much more retained SSL compared to that of water runoff. The hypothesis of sediment management herein is that the amounts of IWR and ISSL are $183 \times 10^{4} \mathrm{~m}^{3}$ and $118 \times 10^{4} \mathrm{t}$, respectively, with an average concentration of $640 \mathrm{~kg} / \mathrm{m}^{3}$. The amounts of IWR and ISSL may count for $1 \%$ and $27 \%$ of that of the total amounts in these ten tributaries, respectively. However, the assumption adopted in Zones 2 and 4 may be different from the actual situation. The annual data provided by YRCC are adopted as baselines (Table 3).

The estimated RD does not mean the 'real' deposition reduction in each river reach. There are two kinds of uncertainties: inner and external. The inner uncertainties are some simplifications made during the analysis procedure. The external uncertainties are other river management measures in different reaches, which are not considered in the comparison.

Simplifications include unified contribution ratio of flood season, unified decreased amounts of IWR and ISSL, and ignoring the effects of drainage area between Toudaoguai-Longmen (TL) and Tongguan-Sanmenxia. Besides, there are various empirical equations for the relationship between source area and deposition area for the YR basin, and different adopted equations may lead to different quantitative descriptions.

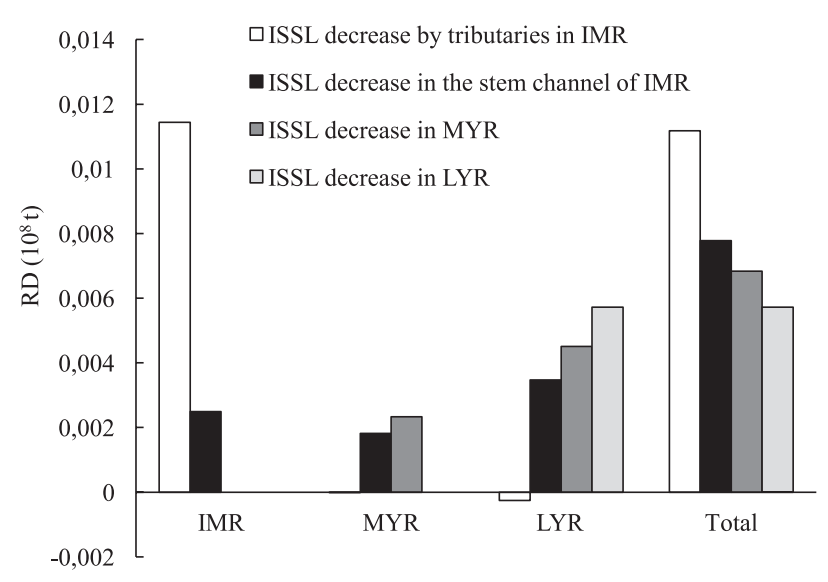

Fig. 2. RD along the Yellow River.
The external uncertainties (i.e., unexpected water and sediment division along river reach) may change the flow and sediment conditions in the river reach, and these factors are not considered during comparison. Furthermore, regulations of the LYR may not be limited to these already existing regulations [47]. The existing regulations and potential regulations in the future may also affect the empirical relationship between inflow and deposition in the LYR, and the external uncertainties may transform to inner uncertainties as varied empirically fitted equations.

\section{Results}

\section{Annual RD}

The estimated annual RD in these three reaches are illustrated in Fig. 2. The connectivity between SWR in Zone 4 and RDP in the LYR is $0.49 \mathrm{t}$.

The connectivity between SWR in Zone 3 and RDP in the LYR is $0.39 \mathrm{t}$, while the RDP in the local river reach (LT reach) is 0.19 t. Thus, SWR measurements in Zone 3 may benefit the local channel (LT reach) and the LYR, while the LYR has more propriety.

The connectivity between SWR in Zone 1 and RD in IMR is $114 \times 10^{4} \mathrm{t}$, while the connectivity between SWR in Zone 2 and RD in IMR is $25 \times 10^{4}$ t. Thus, for RD in the local river reach (IMR), the effect of SWR in Zone 1 is approximately five times that in Zone 2 . On behalf of RD in MYR and LYR, SWR in Zone 1 leads to RD of $-2.6 \times 10^{4} \mathrm{t}$, while the value for SWR in Zone 2 is 53 $\times 10^{4} \mathrm{t}$. On behalf of RD of the whole stem channel of YR (IMR, MYR, and LYR), the contribution by SWR in Zone 1 is $111 \times 10^{4} \mathrm{t}$, while the contribution by SWR in Zone 2 is $78 \times 10^{4} \mathrm{t}$. Thus, for RD in the local (IMR) and followed river reach (MYR and LYR), the effect of SWR in Zone 1 is approximately 1.5 times that in Zone 2 . Thus, to the total RD along the river reach (including IMR, MYR, and LYR), SWR in Zone 1 has more advantage if the amounts of IWR and ISSL are the same.

\section{RD during Non-Flood Season}

As the temporal variation of water runoff and sediment load in the YR basin, contributions in non-flood season are further analyzed. The differences between data estimated in an annual way and flood season may be viewed as contributions in non-flood season. For the MYR, no fitted equation for the annual estimation is listed in Table 2, which can be treated as no contribution during the non-flood season.

Fig. 3 shows the estimated RD during non-flood season along the YR. In total, ISSL decrease during nonflood season in different zones may lead to varied RD along the whole river reach. SWR in Zone 4 during nonflood season may lead to negative RD. This indicates that regulation in flood season is more important in Zone 4. The contribution of SWR in Zone 3 during non-flood 


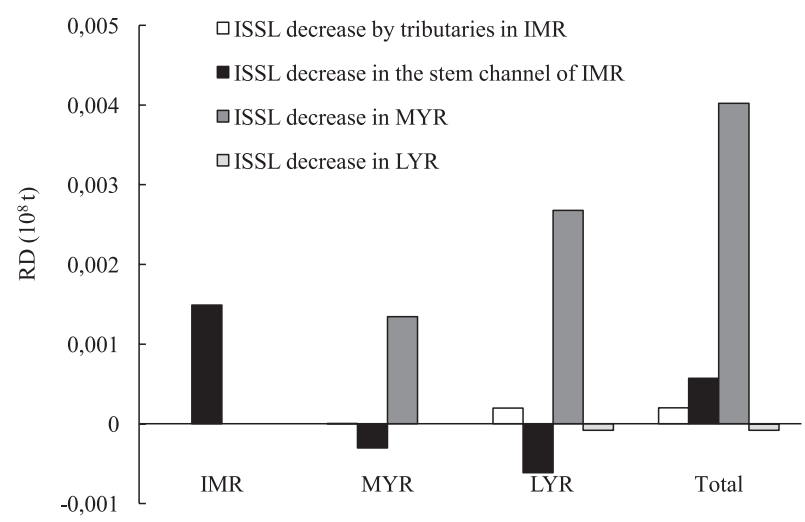

Fig. 3. RD in non-flood season along the Yellow River.

season may contribute to deposition reduction in MYR and LYR. However, the performance of RD caused by an ISSL decrease in Zone 2 is different, positive RD occurred in IMR, while negative RD may occur in MYR and LYR. This indicates the importance of the reservoir operation scheme in non-flood season. The contribution of SWR in Zone 1 during non-flood season may only contribute to deposition reduction in LYR.

\section{Discussion}

Firstly, estimated RD are compared with previous research. Then, the effects of several influencing factors (sedimentation ratio, water division, and ignoring the drainage area between Tongguan-Sanmenxia) which may affect the quantitative description are discussed.

\section{Annual RD Compared with Previous Research}

Several former results are collected and summarized in Table 4 to verify the estimated RD [16, 48-51]. In total, the connectivity between WAR in Zone 3 and RD in the LYR ranges between 0.25-0.9 t. The differences by different reference may be caused by different WSR zones and different sized particles being retained [49].
A comparison indicates that the externally linked models can be used to estimate the coupling connectivity between coarse sediment source areas and deposition area.

More importantly, except for the value of RD along the stem channel, the deposition pattern is another factor needing consideration, especially the LYR [52]. For floods with high concentration, one important factor that influences the deposition pattern is sediment size. Measured data shows that more than $30 \%$ of sediments carried by floods from tributaries of IMR are coarser than $0.025 \mathrm{~mm}$, while more than $83 \%$ of particles in the stem channel of IMR are finer than $0.025 \mathrm{~mm}$. Zhang et al. [53] analyzed the connectivity between sources of flood events (indicating different diameters of transported sediment) and deposition in the main channel and floodplain (also aspect ratio). For SWR in Zones 1 and 2, the RDP in the LYR are $0.18 \mathrm{t}$ and $0.23 \mathrm{t}$, respectively. The main reason may be particle sizes, as particles from the tributary in IMR are coarser than from the stem channel, and ISSL in Zone 1 may tend to be deposited in the local channel (IMR). This is why SWR in tributaries (both IMR and MYR, Zones 1 and 3) are more effective compared to those in the stem channel (Zones 2 and 4). Larger RD in LYR corresponding to SWR in Zone 4 deserves its smallest distance from LYR. This means that the spatial scales over which changes in coupling relationships occur also differ [3].

\section{Deposition in Non-Flood Season}

According to proposed equations for estimating deposition in flood-season and the whole hydraulic year [54], the contribution by SWR in non-flood season can be detected.

$$
\begin{gathered}
\Delta W_{S(3)}{ }^{\prime}=0.887 W_{S(T-L)}{ }^{\prime}-0.130 W_{(T)}{ }^{\prime} \\
\Delta W_{S(3)}=0.839 W_{S(T-L)}-0.398 W_{(T)}
\end{gathered}
$$

...where $\Delta W_{S(3)}$ ' and $\Delta W_{S(3)}$ are depositions in flood season and annual deposition in the Sanmenxia-Lijin reach

\begin{tabular}{|c|c|c|c|}
\hline Drainage area where WSR occurred & River reach where $\mathrm{RD}$ occurred & $\begin{array}{c}\text { Amount of } \\
\operatorname{RDP}(\mathrm{t})\end{array}$ & $\begin{array}{l}\text { Refer- } \\
\text { ence }\end{array}$ \\
\hline Drainage area upper Wubu & LYR & $0.7-0.9$ & \multirow{2}{*}{ [48] } \\
\hline Drainage area upper Longmen & LYR & $0.5-0.7$ & \\
\hline MYR & \multirow{2}{*}{ Sanmenxia reservoir area and LYR } & 0.25 & \multirow{2}{*}{ [49] } \\
\hline SSA & & 0.257 & \\
\hline SSA & LYR & 0.49 & [16] \\
\hline Soil retaining dams in SSA & LYR & 0.25 & [50] \\
\hline \multirow{2}{*}{ Total amount of Longmen, Huaxian, Hejin, and Zhuangtou } & LYR & $0.35-0.48$ & \multirow{2}{*}{ [51] } \\
\hline & Confluence area & $0.14-0.22$ & \\
\hline
\end{tabular}

Table 4. Estimated RD in different river reaches. 
$\left(10^{4} \mathrm{t}\right)$, respectively; $W_{(T)}$ and $W_{(T)}$ ' are the water runoff from drainage area upper Toudaoguai $\left(10^{8} \mathrm{~m}^{3}\right)$, respectively; and $W_{S(T-L)}$ ' and $W_{S(T-L)}$ are the SSL from drainage area between TL $\left(10^{4} \mathrm{t}\right)$, respectively. The two coefficients of the first items on the right-hand side of Eqs. (8) and (9) are almost the same, which indicates the validity of ignoring deposition during non-flood season in MYR (Table 2). The connectivity between SWR in Zone 3 and RD in LYR are $0.45 \times 10^{6} \mathrm{t}$ (hydraulic years) and $0.27 \times 10^{6} \mathrm{t}$ (non-flood season), respectively (as shown in Figs 2 and 3). The two coefficients of the second term on the right-hand-side of Eqs. (8) and (9) indicate the connectivity between water runoff from upper YR (upper Toudaoguai, namely IMR) in non-flood season and deposition in LYR. The connectivity between SWR in Zone 2 and RD in LYR are $0.35 \times 10^{6}$ t (hydraulic years) and $-0.06 \times 10^{6} \mathrm{t}$ (non-flood season), respectively (as shown in Figs 2 and 3). Thus, coefficients in Eqs. (8) and (9) explained the large differences of RD-values in LYR caused by ISSL in Zone 2 and limited differences of RD-values caused by ISSL in Zone 3 (as shown in Figs 2 and 3).

\section{RD Affected by Sedimentation Ratio (SR)}

According to Table 2, the SR of tributaries in IMR [ and ] is 0.968 . The large value of SR indicates that all sediment from Zone 1 may deposit locally. This is the main reason for large RD values in IMR with SWR in Zone 1 (Figs 2 and 3).

$\mathrm{Wu}$ [39] proposed different SRs of the stem channel and tributaries in IMR (Table 5). It shows that the SRs of tributaries are larger than those of the stem channel. Moreover, the SRs of the stem channel and tributaries increase after 1986. The SR for the stem channel by Table 2 (with a value of 0.402) are close to the value after 1986 in Table 5 (with a value of 0.369), while the SR for tributaries in the IMR by Table 2 (with a value of 0.968 ) is much larger than that of in Table 5 (with a value of 0.502 ).

Thus, values of SR fitted by data during 1987-2010 in Table 5 are also adopted to evaluate the RD along the YR to make a comparison (namely values by $\mathrm{Wu}$ [39] and Hou et al. [40]). Fig. 4 shows that the value of SR of tributaries in the IMR may affect the spatial distribution of RD. In total, WSR in Zone 1 may benefit the local channel with a priority ratio, even though the benefit may

Table 5. Values of sedimentation ratio (SR) in the IMR*.

\begin{tabular}{|c|c|c|}
\hline \multicolumn{2}{|c|}{ Sedimentation ratio (\%) } & \multirow{2}{*}{ Data ranges } \\
\cline { 1 - 2 } Main channel & Tributaries & \\
\hline 11.1 & 36.7 & $1953-1986$ \\
\hline 36.9 & 50.2 & $1987-2010$ \\
\hline 16.4 & 42.7 & $1953-2010$ \\
\hline
\end{tabular}

* Data are drawn from $\mathrm{Wu}$ [39].

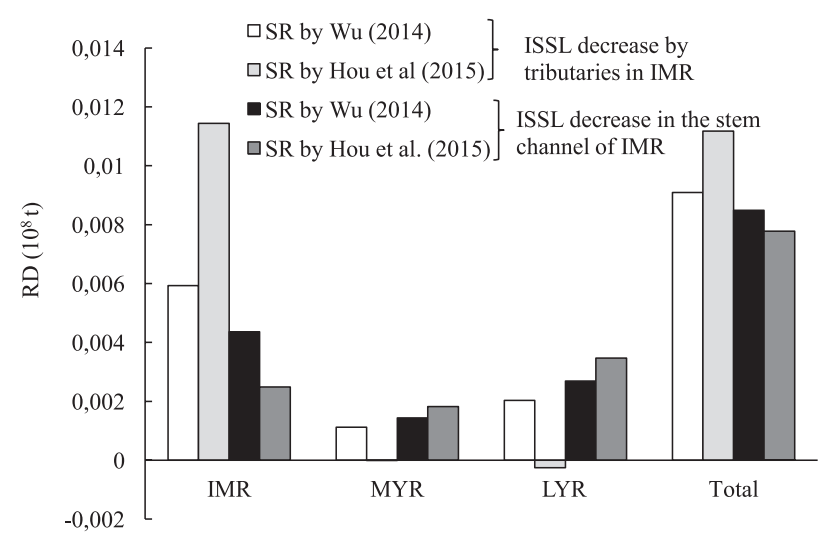

Fig. 4. Effect of SR on RD along the Yellow River.

be dramatically influenced by SR. Benefits of WSR in Zone 2 on the local channel (IMR) and the lower channel (MYR and LYR) are almost the same, as SR may affect the benefit of WSR in Zone 2 with limited magnitude.

Fig. 5 shows the influence during non-flood season by different SR values (values by $\mathrm{Wu}$ [39] and Hou et al. [40]). For non-flood season, only the MYR and LYR may be influenced by ISSL decrease in Zone 1, while the SR values show a distinct influence. For ISSL decrease in Zone 2, the influence of different SR is limited.

Nevertheless the specific values of SR and WSR in Zone 1 lead to larger RD in the IMR. On behalf of MYR and LYR, RD by WSR in Zone 1 are larger than in Zone 2.

\section{Water Division Along the Stem Channel}

As the second largest river in China, the YR may offer water resources for millions of residents, which leads to water-sediment divisions along the YR [55]. The amount of water diverted along the Xiaolangdi-Lijin River reach accounts for $20-30 \%$ of total incoming water [56].

Sediment delivery ratio (SDR) of the LYR may be influence by water division, sediment division, incoming sediment coefficient [ISC, $S_{(3)} / Q_{(3)}$, river self-regulation

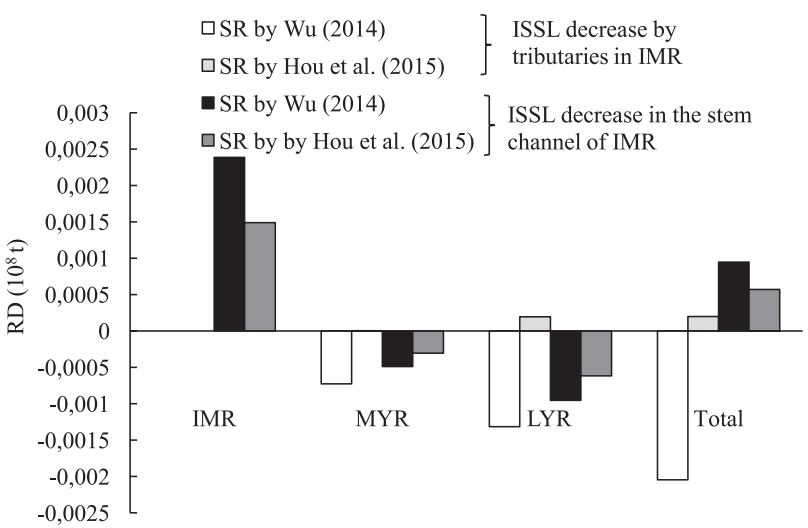

Fig. 5. Effect of SR on RD in non-flood season along the Yellow River. 
Table 6. Relationship between water/sediment diversion and fluvial process in the LYR.

\begin{tabular}{|c|c|c|c|}
\hline Variable 1 & Variable 2 & Relationship & Reference \\
\hline Water diversion & $\begin{array}{l}\text { Fluvial proc- } \\
\quad \text { esses }\end{array}$ & $\begin{array}{l}\text { Water diversion inevitably affects the fluvial processes. } \\
\text { The impacts of runoff reduction on the fluvial processes were channel } \\
\text { shrinkage and the adjustment of the riverbed profile. } \\
\text { The large quantity of water diverted along the course of the Yellow River } \\
\text { makes the term } S \mathrm{~d} Q / \mathrm{d} x \text { negative. }\end{array}$ & {$[57]^{1}$} \\
\hline Water diversion & $\begin{array}{c}\text { Fluvial } \\
\text { processes }\end{array}$ & $\begin{array}{l}\text { If a } 35 \% \text { diversion rate happens, the increased volume of silting is } 0.38 \\
\text { billion tons and the increased rate is } 32 \% \text {. } \\
\text { The ratio of scour and fill change value over incoming water value will } \\
\text { increase when the diversion increases. }\end{array}$ & {$[56]^{2}$} \\
\hline Sediment diversion & $\begin{array}{c}\text { Fluvial } \\
\text { processes }\end{array}$ & $\begin{array}{l}\eta<0.05 S D R=0.0818\left(\frac{S_{(3)}}{Q_{(3)}}\right)^{-0.559} 0.0006<\left(\frac{S_{(3)}}{Q_{(3)}}\right)<0.1 \\
\eta<0.10 S D R=0.0872\left(\frac{S_{(3)}}{Q_{(3)}}\right)^{-0.539} \quad 0.0006<\left(\frac{S_{(3)}}{Q_{(3)}}\right)<0.15\end{array}$ & {$[33]^{3}$} \\
\hline $\begin{array}{l}\text { Water from upper YR, } \\
\text { sediment from CSA }\end{array}$ & $\begin{array}{c}\text { Fluvial } \\
\text { processes }\end{array}$ & $S D R=W_{S(T-L)}^{-0.581} W_{(T)}^{0.388}$ & {$[54]^{4}$} \\
\hline Water entering the LYR & $\begin{array}{l}\text { Fluvial } \\
\text { processes }\end{array}$ & $S D R=0.0837\left(\sum Q_{d(3)}{ }^{2}\right)^{0.048}\left(S_{(3)} / Q_{(3)}\right)^{-0.56}$ & {$[42]^{4}$} \\
\hline
\end{tabular}

${ }^{1} S$ is the riverbed slope; $Q$ is the discharge in $\mathrm{m}^{3} / \mathrm{s} ; x$ is the distance along the river course in $\mathrm{km}$.

${ }^{2} S_{0}$ is the sediment carrying capacity before diversion; $S_{\eta}$ is the sediment carrying capacity after diversion; $R \mathrm{~s}$ is the channel changes of scour and fill; $S$ is the annual mean sediment concentration rate of outflow $\left(\mathrm{kg} / \mathrm{m}^{3}\right) ; W \mathrm{~s}$ and $W \mathrm{q}$ are the annual mean sediment volume $\left(10^{7} \mathrm{t}\right)$ and water volume $\left(10^{7} \mathrm{~m}^{3}\right)$ of outflow respectively. $\eta$ is water diversion rate, and it can be calculated as $\eta=$ runoff at (Xiaolangdi+Heishiguan + Xiaodong-Lijin)/runoff at (Xiaolangdi + Heishiguan + Xiaodong).

${ }^{3} S_{(0)}=W_{S(3)}{ }^{1 /} W_{(3)}{ }^{\prime}$ with unit of $\mathrm{kg} / \mathrm{m}^{3}, Q_{(3)}=1157.470 \cdot W_{(3)}{ }^{\prime} / T$ with unit of $\mathrm{m}^{3} / \mathrm{s}, T$ is the days of flood events; sediment diversion ratio $\eta$ is calculated as $\eta=W_{s, d} / W_{S(3)}$, in which $W_{\mathrm{s}, \mathrm{d}}$ is the diverted sediment load and $W_{\mathrm{s}, \mathrm{in}}$ is the observed SSL at the entrance of the LYR. The sediment diversion ratio varies from 0.05 to 0.50 (based on 277 flood events during 1950-1986).

${ }^{4} \mathrm{~S} D R$ is the sediment diversion ratio, $W_{(\mathrm{T})}$ is the water runoff from drainage area upper Toudaoguai $\left(10^{8} \mathrm{~m}^{3}\right)$, and $W_{\mathrm{S}(\mathrm{T}-\mathrm{L})}$ is the SSL from drainage area between Toudaoguai and Longmen $\left(10^{4} \mathrm{t}\right)$.

${ }^{5} \Sigma Q_{d(3)}{ }^{2}$ represents the annual sediment-carrying capacity of streamflow, and can be calculated by data at Huayuankou with unit of $10^{8}$ $\mathrm{m}^{6} / \mathrm{s}^{2} ; S_{(3)} / Q_{(3)}$ can be calculate by mean annual suspended concentration and water discharge with unit of $\mathrm{kg} . \mathrm{s} / \mathrm{m}^{6}$.

processes, and human activities [33, 56]. Moreover, SDR in the LYR may also depend on water runoff from IMR $\left[W_{(\mathrm{T})}\right]$ and SSL from MYR [ $\left.W_{\mathrm{S}(\mathrm{T}-\mathrm{L})}\right]$ [54]. The exponent coefficients of $W_{(\mathrm{T})}$ and $W_{\mathrm{S}(\mathrm{T}-\mathrm{L})}$ are 0.388 and 0.581 , respectively, while the exponent of $S_{(3)} / Q_{(3)}$ is approximately $0.5[33,42,57]$. This indicates that the influence of decreased IWR in Zone 2 is close to that of decreased ISSL in Zone 3 and ISC in Zone 4. The SR may increase with increased water diversion rate [56]. In total, increased water diversion rate may reduce the influence of WSR in the upper and middle drainage area on deposition reduction in the lower part (Table 6).

\section{Drainage Area between Tongguan-Sanmenxia}

The inflow conditions (both of the runoff and SSL) of the LT reach used are data measured at Longmen and Hejin stations (Table 2). Fig. 1b shows that runoff from the Wei and Beiluo rivers may also contribute to the flow regime at Tongguan station. Both the annual runoff and runoff in flood season at Tongguan station may contribute to Tongguan elevation (listed in Table 7, Wu [36]), while raised Tongguan elevation may contribute to deposition in the LT reach by a changed benchmark.

In addition, sediment eroded from the Beiluo and Jing rivers join the YR at Tongguan station, and these two parts of the drainage area are parts of the SSA. Sediment eroded from the drainage area between TongguanSanmenxia counts for approximately $33.9 \%$ of the total sediment in the LYR. Sediment contributed by these two tributaries may change the sediment regime of Tongguan station and deposition in the LT reach followed.

The operational scheme of Sanmenxia Reservoir, which may affect the flow conditions entering the LYR, depends on flow from the upper and middle river reach [58]. Thus, the operation of Sanmenxia Reservoir makes the connection of these two areas (MYR and LYR) much more complex.

\section{Implications}

Sediment is a natural and essential component of a river system, and information on sediment can provide an important support for water resource development and management [59]. The effect of sediment management is 
Table 7. Influence of the conjunction area.

\begin{tabular}{|c|c|c|c|}
\hline Variable 1 & Variable 2 & Relationship & Reference \\
\hline & & $Z_{t g}=-0.0005 W_{a}+328.95\left(R^{2}=0.65\right)$ & \\
Changes in flow runoff at Tongguan & Tongguan & $Z_{t g}=-0.00061 W_{f}+328.37\left(R^{2}=0.62\right)$ & {$[36]^{1}$} \\
& elevation & $\Delta Z_{t g}=0.049-0.016 \Delta E-5 \times 10^{-5} \Delta E^{2}\left(R^{2}=0.72\right)$ & \\
\hline
\end{tabular}

${ }^{1} Z_{\mathrm{tg}}$ is the elevation of Tongguan measured at the end of the flood season $(\mathrm{m}) ; W_{\mathrm{a}}$ is the annual runoff at Tongguan station $\left(10^{9} \mathrm{~m}^{3}\right)$; $W_{\mathrm{f}}$ is the runoff in the flood season at Tongguan station $\left(10^{9} \mathrm{~m}^{3}\right) ; E$ is the annual stream energy per unit length $\left(10^{9} \mathrm{~J} / \mathrm{m}\right)$.

widespread, and coupled analysis and judging the effects of sediment-related measurements in zonal-scale are necessary.

The loosely coupled evaluation herein may provide information of sediment along the whole river network, and the connectivity between sediment interception in source areas and deposition in the sedimentation area is an insight into the tightly connected network system. It is hopefully to help in projecting changes in hydrology due to changes in land use and providing implications to river management even though there are several other assumptions (i.e., the simplified ratio for flood season) [60]. The analysis may lead to a better understanding of the hydrological, geomorphologic, and ecological function of a whole river system.

In total, less deposition in the LYR leads to less water runoff for transporting sediment into sea [61]. The reduced flushing water runoff can be used in industry, agriculture, and residuals, which leads to huge economic benefits. SWR in the upper drainage area not only helps reduce sediment load entering LYR, but also helps save flushing water runoff needed in each river reach. More importantly, the effects of water-sediment regulation scheme that already existed in LYR (Xiaolangdi and Sanmenxia reservoirs) decreases, and the function shows a decreased trend $[62,63]$. Thus, the new water-sediment regulation scheme in the LYR may be necessary in order to meet the new SWR in hillslopes. Besides, the reservoir operation scheme on the IMR in non-flood season is also important for the lower channel.

\section{Conclusions}

The coupling mechanisms between sediment sources and the channel network in the YR is analyzed by looselylinked models. Analysis shows that:

1) Sediment management in different tributaries and stem channels may lead to different spatial distribution of deposition reduction along the river reach.

2) At zonal scale, the connectivity between changes in different zones and deposition reduction in different river reaches differ. SWR in Zone 1 may benefit the local channel (IMR) with a priority ratio; SWR in Zone 2 may benefit both the local channel (IMR) and the lower channel (LYR) with almost the same magnitude; and SWR in Zone 3 may benefit the local channel (LT reach) and the lower channel (LYR), while the LYR has more propriety.

3) At zonal scale, the temporal scales over which changes in hillslopes occur also differ, as SWR in tributaries (both of tributaries entering the IMY and MYR) during non-flood season may also contribute to deposition reduction in the MYR and LYR.

In total, the effects of sediment-water retaining measurements in the upland should be evaluated in the whole river system.

\section{Acknowledgements}

This work was supported by 1) the National Natural Science Foundation of China (Nos. 2016YFC0402503, 51579230, 41571005, and 51109198) and 2) the National Key Technology R\&D Program of China (Nos. 2011CB403305 and 2012BAB02B02).

\section{Conflict of Interest}

The authors declare no conflict of interest.

\section{References}

1. BRUNSDEN D., THORNES J.B. Landscape sensitivity and change. Institute of British Geographers Transactions, New Series, 4, 463, 1979.

2. HARVEY A.M. Coupling between hillslopes and channels in upland fluvial systems: implications for landscape sensitivity, illustrated from the Howgill Fells, northwest England. Catena, 42, 225, 2001.

3. HARVEY A.M. Effective timescales of coupling within fluvial systems. Geomorphology, 44, 175, 2002

4. KUO C.W., BRIERLEY G. The influence of landscape connectivity and landslide dynamics upon channel adjustments and sediment flux in the Liwu Basin, Taiwan. Earth Surface Processes and Landforms, 39(15), 20382055, 2014.

5. HOOKE J.M. Coarse sediment connectivity in river channel systems: a conceptual framework and methodology. Geomorphology, 56, 79, 2007.

6. FRYIRS K.A., BRIERLEY G.J., PRESTON N.J., SPENCER J. Catchment scale (dis)connectivity in sediment flux in the upper Hunter catchment, New South Wales, Australia. Geomorphology, 84, 297, 2007. 
7. HE L. Effects of human activities in the Wei River basin on the Lower Yellow River, China. Pol. J. Environ. Stud., 26 (6), 1, 2017.

8. HARVEY A.M. The coupling status of alluvial fans and debris cone: a review and synthesis. Earth Surface Processes and Landforms, 37, 64, 2012.

9. HASSAN M.A., ROBERGE L., CHURCH M., MORE M., DONNER S.D., LEACH J., ALI K.F. What are the contemporary sources of sediment in the Mississippi River? Geophysical Research Letters, 44 (17), 8919, 2017.

10. BERGILLOS R.J., MASSELINK G., ORTEGASANCHEZ M. Coupling cross-shore and longshore sediment transport to model storm response along a mixed sand-gravel coast under varying wave directions. Coastal Engineering, 129, 93, 2017.

11. FULLER I.C., RIEDLER R.A., BELL R., MARDEN M., GLADE T. Landslide-driven erosion and slope-channel coupling in steep, forested terrain, Ruahine Ranges, New Zealand, 1946-2011. Catena, 142, 252, 2016.

12. JONES A.P. Late quaternary sediment sources, storage and transfers within mountain basins, using clast lithological analysis: Pineta basin, central Pyrenees, Spain. Geomorphology. 34 (3-4), 145, 2000. DOI: 10.1016/S0169555X(00)00004-0

13. POEPPL R.E., KEESSTRA S.D., MAROULIS J. A conceptual connectivity framework for understanding geomorphic change in human-impacted fluvial systems. Geomorphology, 277, 237, 2017.

14. XU E.G., CHAN S.N., CHOI K.W., LEE J.H.W., LEUNG K.M.Y. Tracking major endocrine disruptors in coastal waters using an integrative approach coupling fieldbased study and hydrodynamic modeling. Environmental Pollution, 233, 387, 2018.

15. DEBELE B., SRINIVASAN R., PARLANGE J.-Y. Coupling upland watershed and downstream waterbody hydrodynamic and water quality models (SWAT and CEQUAL-W2) for better water resources management in complex river basins. Environ Model Assess, 13, 135, 2008.

16. XU Z.Y., GODREY A.N., GRIZZARD T.J. The hydrological calibration and validation of a complexlylinked watershed-reservoir model for the Occoquan watershed, Virginia. Journal of Hydrology, 345, 167, 2007.

17. HE L., WANG G.Q., ZHANG C. Application of loosely coupled watershed model and channel model in Yellow River. Journal of Environmental Informatics, 19 (1), 30, 2012.

18. CORANI G., GUARISO G. Coupling fuzzy modelling and neural networks for river flood prediction. IEEE Transactions on Systems, Man and Cybernerics, Part C: Applications and Reviews, 35 (3), 3820, 2005.

19. CHEN F., XIE Z.H. A large-scale routing scheme for stream simulation and its application to river basins in China. Proceedings of Chinese PUB International Symposium, Beijing, China, 65, 2008.

20. SURIAN N., CISOTTO A. Channel adjustments, bedload transport and sediment sources in gravel-bed river, Brenta River, Italy. Earth Surface Processes and Landforms, 32 (11), 1641, 2007.

21. GREGORY K.J. The human role in changing river channels. Geomorphology, 79 (1), 172, 2006.

22. ZHENG S., WU B.S. Simulation of sedimentation processes of the Xiaobeiganliu reach of the Yellow River and the lower Wei River. Journal of Hydraulic Engineering, 45 (2), 150, 2014.

23. HE L., WANG G.Q., LI T.J. Catchment division of the water and sediment yield system and drainage network codification of the key region in the middle Yellow River Basin. Journal of Sediment Research, 2, 39, 2009 [In Chinese with English abstract].

24. XU J.X. Sediment jamming of a trunk stream by hyperconcentrated floods from small tributaries: case of the Upper Yellow River, China. Hydrological Sciences Journal, 61 (10), $150714054254009,2015$.

25. FAN X.L., SHI C.X., ZHOU Y.Y., SHAO W.W. Sediment rating curves in the Ningxia-Inner Mongolia reaches of the upper Yellow River and their implications. Quaternary International, 282, 152, 2012.

26. ZHI J.F., SHI M.L. Deposition of floods from ten tributaries in the upper Yellow River [M]. Wang, G., Fan, Z. Variation of water-sediment in the Yellow River Basin. The Yellow River Water Conservancy Press: Zhengzhou, China, 460, 2002 [In Chinese with English abstract].

27. MICHAELIDES K., SINGER M.B. Impact of coarse sediment supply from hillslopes to the channel in runoff-dominated, dryland fluvial systems. Journal of Geophysical Research: Earth Surface, 120, 2014.

28. MUELLER E.R., PITLICK J. Sediment supply and channel morphology in mountain river systems: 2 . Single thread to braided transitions. Journal of Geophysical Research: Earth Surface, 1516, 2014.

29. COULThARD T.J., DE WIEL M.J.V. Modelling long term basin scale sediment connectivity, driven by spatial land use changes. Geomorphology, 277, 265, 2017.

30. SAVI S., SCHNEUWLY-BOLLSCHWEILER M., BOMMER-DENNS B., STOFFEL M., SCHLUNEGGER F. Geomorphic coupling between hillslopes and channels in the Swiss Alps. Earth Surf Process Landforms, 38, 959, 2013.

31. CAVALLI M., TREVISANI S., COMITI F., MARCHI L. Geomorphometric assessment of spatial sediment connectivity in small Alpine catchments. Geomorphology, 188, 31, 2013.

32. ZHENG S., WU B.S. Simulation of the sedimentation processes of the Xiaobeiganliu Reach, Yellow River and the Lower Wei River. Proceedings of the $35^{\text {th }}$ IAHR World Congress, Vols I and II, 4361, 2013.

33. FU X.D., JIANG L.W., WU B.S., HU C.H. WANG G.Q., FEI X.J Sediment delivery ratio and its uncertainties on flood event scale: quantification for the Lower Yellow River. Science China-Technological Sciences, 53 (3), 854, 2010.

34. SHI C.X. Decadal trends and causes of sedimentation in the Inner Mongolia reach of the upper Yellow River, China. Hydrological Processes, 30, 232, 2016.

35. YAO H.F., SHI C.X., SHAO W.W., BAI J.B., YANG H. Changes and influencing factors of the sediment load in the Xiliugou basin of the upper Yellow River, China. Catena, $142,1,2016$.

36. WU B.S., WANG G.Q., WANG Z.Y., XIA J.Q. Effect of changes in flow runoff on the elevation of Tongguan in Sanmenxia Reservoir. Chinese Science Bulletin, 49(15), $1658,2004$.

37. JING K., LI J.Z., LI F.X. Ratio producing runoff and sediment from more sediment and coarse sediment region occupying total runoff and sediment in the Middle Reaches of Yellow River. Journal of soil erosion and soil and water conservation, 5 (1), 13, 1999 [In Chinese].

38. RAN D.C., LUO Q.H., ZHOU Z.H., WANG G.Q., ZHANG X.H. Sediment retention by check dams in the Hekouzhen- 
Longmen Section of the Yellow River. International Journal of Sediment Research, 23, 159, 2008.

39. WU B.S. Effect of the ten major tributaries in the Inner Mongolia on runoff and sediment load as well as sedimentation in the main stream of the Yellow River. Yellow River, 36 (10), 5, 2014 [In Chinese with English abstract].

40. HOU S.Z., WANG P., LIN X.Z, et al. Technical report of hyper-concentrated floods' control in tributaries of the Inner Mongolia reach, Yellow River. The Yellow River Hydraulic Research Institute. 2015 [In Chinese].

41. WU B.S., WANG P., ZHANG Y.F. Fluvial evolution of the Inner Mongolia River, Yellow River. Science Press: Beijing, China, 2016 [In Chinese].

42. XU J.X. Effect of human activities on overall trend of sedimentation in the Lower Yellow River, China. Environmental Management, 33 (5), 637, 2004.

43. WU B.S., ZHANG Y.F., SHEN G.Q. Water and sediment conditions for the main channel of the Yellow River [M]. The Yellow River Water Conservancy Press: Zhengzhou, China, 2010 [In Chinese].

44. WU B.S., ZHENG S. Theory and application of the morphological response in fluvial system. China Water Power Press: Beijing, China, 2015 [in Chinese].

45. FAN L.J., HUANG C.C., PANG J.L., ZHA X.C., ZHOU Y.L., LI X.G., LIU T. Sedimentary records of palaeo floods in the Wubu reach along Jin-Shaan gorges of the middle Yellow River, China. Quaternary International, 380-381, 368, 2015.

46. XU J.X. The influence of dilution on downstream channel sedimentation in large rivers: the Yellow River, China. Earth Surface Processes and Landforms, 39, 450, 2014.

47. SUN Z.Y., WANG W.Z., LI Y., ZHANG M.W., SHANG H.X., ZHANG F.X. Can the narrowing of the Lower Yellow River by regulation result in non-siltation and even channel souring? J. Geogr. Sci., 26 (9), 1337, 2016.

48. ZHANG R. Effects of coarse sediment retention on the tem channel of Yellow River. The Yellow River Water Conservancy Press: Zhengzhou, China, 1998 [In Chinese].

49. HE X.H., GAO Y.J., LI X.Y., XU J.H. Sediment impacts of incoming sediment from different areas of the middle reaches of the Yellow River on Sanmenxia Reservoir and its downstream area. Bulletin of Soil and Water Conservation, 28 (6), 86, 2008 [In Chinese].

50. 5RAN D.C., YAO W.Y., LI Z.B., LUO Q.H. Study on sediment reduction effect by soil retaining dam with different storage capacity allocation proportion in Dali river watershed. Advanced Materials Research, 779, 2013.

51. SHEN G.Q., LI Y., YUE D.J., HAN Q.L., ZHOU W.Z. Effect of retaining coarse sediment on sedimentation reduction in the Lower Yellow River. Yellow River, 22 (6), 13, 2000 [In Chinese with English abstract].
52. TIAN S.M., WANG W.H., XIE B.F., ZHANG M. Fluvial processes of the downstream reaches of the reservoirs in the Lower Yellow River. J. Geogr. Sci., 26 (9), 1321, 2016.

53. ZHANG O.Y., XU J.X., ZHANG H.W. Impact of flood events from different source areas on channel transects adjustment at the wandering-braided reach of the lower Yellow River. Journal of Sediment Research, 6, 1, 2002 [In Chinese with English Abstract].

54. XU J.X. Sedimentation and sediment transport in Lower Yellow River as influenced by coupling of water and sediment yield in upper drainage basin. Journal of Sediment Research, 3, 49, 2011 [In Chinese with English abstract].

55. GUO P., MENG X.M., LI Y.J., CHEN G., ZENG R.Q., QIAO L. Effect of large dams and irrigation in the upper reaches of the Yellow River of China, and the geohazards burden. Proceedings of the Geologists' Association, 126, 367, 2015.

56. HU C.H., GUO Q.C. Modeling sediment transport in the lower Yellow River and dynamic equilibrium threshold value. Science in China Ser. E., 47 (Supp. I), 161, 2004.

57. WANG Z.Y., WU B.S., WANG G.Q. Fluvial processes and morphological response in the Yellow and Wei Rivers to closure and operation of Sanmenxia Dam. Geomorphology, 91, 65, 2007.

58. ZHAO G.J., MU X.M., STREHMEL A., TIAN P. Temporal variation of streamflow, sediment load and their relationship in the Yellow River Basin, China. PLOS, 9 (3), e91048, 2014.

59. SAMPSON A.A. The assessment of suspended sediment inputs to Volta Lake. Lakes \& Reservoirs: Research and Management, 10 (3), 179, 2005.

60. OWENS P.N., BATALLA R.J., COLLINS A.J. Finegrained sediment in river systems: environmental significance and management issues. River Research and Applications, 21 (7), 693, 2005.

61. RAN D.C., LUO Q.H., LIU B., WANG H. Effect of soilretaining dams on flood and sediment reduction in middle reaches of Yellow River. Shuili Xuebao, 5, 7, 2004 [In Chinese with English Abstract].

62. KONG D.X., MIAO C.Y., WU J.W., BORTHWICK A.G.L., DUAN Q.Y., ZHANG X.M. Environmental impact assessments of the Xiaolangdi Reservoir on the most hyperconcentrated laden river, Yellow River, China. Environ Sci Pollut Res., DOI 10.1007/s11356-016-7975-4, 2016.

63. MIAO C.Y., KONG D.X., WU J.W., DUAN Q.Y. Functional degradation of the water-sediment regulation scheme in the lower Yellow River: spatial and temporal analysis. Science of the Total Environment, 551-552, 16-, 2016. 
